\title{
Historical and Future Changes in Asset Value and GDP in Areas Exposed to Tropical Cyclones in China
}

\author{
MENGQI YE AND JIDONG WU \\ Key Laboratory of Environmental Change and Natural Disaster, Ministry of Education, and State Key Laboratory of Earth Surface \\ Processes and Resource Ecology, Faculty of Geographical Science, Beijing Normal University, Beijing, China
}

\section{CAILIN WANG AND Xin He}

State Key Laboratory of Earth Surface Processes and Resource Ecology, Faculty of Geographical Science, Beijing Normal University, Beijing, China

(Manuscript received 14 May 2018, in final form 29 November 2018)

\begin{abstract}
Tropical cyclones (TCs) can wreak havoc on the landscape and overwhelm communities. Since economic exposure is an important factor in damage function, an evaluation of economic exposure is essential because the characteristics of TC-related hazards are changing under accelerating economic development patterns. Here, we first reconstructed the wind and rainfall fields of historical TCs through an extensive database to extract the economic exposure to TC-prone areas on the mainland of China. We found that rainfall is an important factor in determining the affected extent of a TC event and that economic exposure will be misestimated when considering only the wind field. The results reveal that economic exposure to TCs has increased considerably from 1990 to 2015 and will continue to increase until the year 2100 under shared socioeconomic pathways (SSPs). We found that $66.7 \%$ of China's gross domestic product [GDP; CNY 48.6 trillion (7.8 trillion U.S. dollars)] and $63.9 \%$ of China's asset value [CNY 139.5 trillion (22.4 trillion U.S. dollars)] were concentrated in TC-prone areas in 2015 and increased at an average annual rate of $10.6 \%$ and $13.9 \%$, respectively. Projections of GDP scenarios under SSPs revealed continued growth in the early twentyfirst century, and the range of GDP and asset value in TC-prone areas by 2100 varied. Further detailed studies are needed to provide a detailed damage function for TC loss assessments under climate change and to consider how TC hazards will interact under changes in exposure and vulnerability related to economic development and social change.
\end{abstract}

\section{Introduction}

Tropical cyclones (TCs) are characterized by strong winds, torrential rainfall, coastal flooding, and storm surges and represent one of the costliest natural hazardinduced disasters; TCs threaten the life and property along coasts and inflict devastating casualties and economic damage (Mori and Takemi 2016; Peduzzi et al. 2012; Pielke et al. 2008). The annual direct economic losses (DELs) arising from landfalling TCs in China have been estimated at approximately CNY 28.7 billion (2006 price levels), which is equal to $0.38 \%$ of China's annual gross domestic product (GDP) from 1983 to 2006 (Zhang et al. 2009). In 2013, 13 TCs struck coastal provinces of China, causing 179 deaths and claiming total DELs of CNY 126.0 billion (CMA 2014).

Corresponding author: Jidong Wu, wujidong@bnu.edu.cn
With the ongoing development of the Chinese economy and society, the increasing exposure to hazards has further increased the risk from natural hazard-induced disasters (Rosencrants and Ashley 2015). The population of China has increased in recent decades, with $55.6 \%$ dwelling in urban areas in 2015 , which is twice the proportion observed in 1990 (26.4\%), and another 270.5 million are expected by the end of 2050, as estimated by the United Nations (2015). Regardless of the potential changes in TC characteristics, economic growth produces more "targets" for TCs to strike. In that respect, these losses and damage will not occur if exposure is prevented (Ashley et al. 2014; Freeman and Ashley 2017). Therefore, to understand the potential loss of life and socioeconomic damage caused by TCs, we must determine how TCs will change in frequency and intensity in the context of future climate change and how these hazards will interact with the changing exposure associated 
with economic progress and social development (Ashley and Strader 2016; Freeman and Ashley 2017; Geiger et al. 2016; Mendelsohn et al. 2012; Noy 2016).

In this study, economic exposure is defined as an asset value involving physical assets (buildings) and nonbuilding infrastructure as well as GDP (Gunasekera et al. 2015; Wu et al. 2017). The majority of studies focused on TCs have analyzed certain characteristics such as the intensity, frequency, track migration, and duration via statistical methods, theoretical modeling, and numerical simulations (Camargo and Sobel 2005; Elsner et al. 2008; Knutson et al. 2010; Vecchi and Soden 2007). Exposure to hazards is an essential factor in both loss assessment and risk analysis and a key driver of the severity of economic losses and damage (Ashley et al. 2014); nevertheless, there is a dearth of research focusing specifically on the socioeconomic characteristics of the economic losses and damage caused by TC events. Hence, further studies on the temporal and spatial variations of economic exposure to TCs are essential to assess the associated loss and risk and to further support adaption measures.

One of the key issues to be addressed for economic exposure estimations for TCs is identifying the TC-affected extent. Several studies have modeled TC-affected extents by exclusively considering the wind field (Geiger et al. 2016; Hsiang and Jina 2014; Mendelsohn et al. 2012) or the path width of each TC based on the intensity category (Woodruff et al. 2013; Geiger et al. 2016; Freeman and Ashley 2017). However, for a certain TC, rainfall is likely as destructive as the wind factor with regard to its contribution to disastrous impacts (Breña-Naranjo et al. 2015; Bakkensen et al. 2018). In 2006, for example, the water vapor carried by the severe Tropical Storm Bilis (0604) was twice as large as that of Supertyphoon Saomai (0608), which had amplified the energy of Bilis and kept it on China's mainland for 5 days, thus causing DELs twice as high as those caused by Saomai (Chen et al. 2011).

To fill these gaps, the main aim of this study was twofold: 1) to determine the TC-affected extent based on the impact of wind speed and precipitation and assess how TC-induced rainfall affects economic exposure estimations at the TC level and 2) to analyze the spatiotemporal variations of GDP and asset value exposed to TCs from 1990 to 2100 on the mainland of China. Given the considerable uncertainties involved in projecting changes in TC activities under future climate change (Murakami et al. 2012), we estimated only the impact of socioeconomic change when projecting future TC economic exposure change and held TC activity constant at its current condition. Effective economic exposure estimations are helpful for improving loss estimation models and understanding of the complex relationship among the three elements of disaster risk (hazard, exposure, and vulnerability).

\section{Data and methods}

\section{a. Data sources}

This study used six datasets (Table 1). First, the best track dataset for TCs over the western North Pacific (WNP) from 2000 to 2015 was downloaded from the China Meteorological Administration (CMA; tcdata. typhoon.org.cn; Ying et al. 2014). Each best track record includes the TC intensity category, the location of the TC center, the minimum pressure, and the 2-min mean maximum sustained wind near the TC center every $6 \mathrm{~h}$.

Second, precipitation data of the Tropical Rainfall Measurement Mission (TRMM) Multisatellite Precipitation Analysis (TMPA) were downloaded from the NASA Goddard Earth Sciences Data and Information Services Center (GES DISC; Huffman 2016), which provides rainfall information from 2000 to 2015 at $0.25^{\circ}$ resolution from $60^{\circ} \mathrm{N}$ to $60^{\circ} \mathrm{S}$ from multiple TRMM satellites every $3 \mathrm{~h}$. This precipitation dataset has been demonstrated to have good consistency with rain gauge records and radar observations (Huffman et al. 2007; Huffman 2016; Luo et al. 2011; Moazami et al. 2013).

Third, GDP data at the county level of China in 1990, 2000, 2010, and 2015 were obtained from the China Statistical Yearbooks Database (CSYD; data.cnki.net), which contains most of the statistical yearbooks at the national, provincial, and county scales and is published by the China Statistics Press.

Fourth, asset value (or capital stock) data at the prefectural level of China in 1990, 2000, 2010, and 2015 were produced by $\mathrm{Wu}$ et al. $(2014,2018 \mathrm{~b})$ and provide the prefectural asset value in China based on statistical data through the perpetual inventory method (PIM). For a given county, county-level asset value data were estimated based on its GDP and multiplied by the prefectural capital-output ratio (Wu et al. 2017). The provincial-level asset value exposed to each TC was measured by aggregating the county-level asset value.

Fifth, long-term Chinese economic growth projections under the shared socioeconomic pathways (SSPs) with GDP scenarios (i.e., SSP1, SSP2, and SSP3) in $0.5^{\circ} \times 0.5^{\circ}$ grids from 1990 to 2100 in increments of 10 years were downloaded from the Center for Global Environmental Research (CGER; http://www.cger.nies.go.jp/en/; Murakami and Yamagata 2016). We used the annual GDP growth rate in China calculated based on CGER's dataset 
TABLE 1. Data used in the study and sources.

\begin{tabular}{|c|c|c|c|}
\hline Data name & Regions and periods & Resolution & Source \\
\hline Tropical cyclone track dataset & $\begin{array}{l}\text { Western North Pacific, } \\
\text { 2000-15 }\end{array}$ & Per TC event & $\begin{array}{l}\text { Shanghai Typhoon Institute of } \\
\text { CMA (tcdata.typhoon.org.cn) }\end{array}$ \\
\hline $\begin{array}{l}\text { TRMM multisatellite precipitation } \\
\text { analysis data }\end{array}$ & $60^{\circ} \mathrm{N}-60^{\circ} \mathrm{S}, 2000-15$ & $0.25^{\circ} \times 0.25^{\circ}, 3 \mathrm{~h}$ & Huffman (2016) \\
\hline Asset value & 1990, 2000, 2010, 2015 & Prefectural level of China & Wu et al. $(2014,2018 b)$ \\
\hline GDP & $1990,2000,2010,2015$ & County level of China & $\begin{array}{l}\text { China Statistical Yearbooks } \\
\text { Database (data.cnki.net) }\end{array}$ \\
\hline Global dataset of GDP scenarios & $\begin{array}{l}\text { 1990-2100, in } 10-\mathrm{yr} \\
\text { increments }\end{array}$ & $0.5^{\circ} \times 0.5^{\circ}$ & $\begin{array}{l}\text { Murakami and Yamagata (2016); } \\
\text { http://www.cger.nies.go.jp/en }\end{array}$ \\
\hline $\begin{array}{l}\text { Historical TC-induced DELs } \\
\text { dataset (a) }\end{array}$ & 1990-2015 & Provincial level of China & CMA (various years; e.g., CMA 2015) \\
\hline $\begin{array}{l}\text { Historical TC-induced DELs } \\
\text { dataset (b) }\end{array}$ & $2009-15$ & County level of China & $\begin{array}{l}\text { National Disaster Reduction Center } \\
\text { of China, Ministry of Civil Affairs }\end{array}$ \\
\hline $\begin{array}{l}\text { Price indices of investment } \\
\text { in fixed assets }\end{array}$ & $1990-2015$ & Provincial level of China & $\begin{array}{l}\text { China Statistical Yearbooks Database } \\
\text { (data.cnki.net) }\end{array}$ \\
\hline Consumer Price Index & $1990-2015$ & China & $\begin{array}{l}\text { China Statistical Yearbooks Database } \\
\text { (data.cnki.net) }\end{array}$ \\
\hline GDP deflator & $1990-2015$ & China & $\begin{array}{l}\text { World Development Indicators } \\
\text { from the World Bank } \\
\text { (http://data.worldbank.org/data-catalog/ } \\
\text { world-development-indicators) }\end{array}$ \\
\hline
\end{tabular}

instead of the specific GDP levels [initial data are presented in 2005 U.S. dollars (USD)].

Sixth, a historical TC-induced DELs dataset from 1990 to 2015 at the provincial level was collected from the China Climate Impact Assessment [various years from 1990 to 2015; e.g., CMA (2015)], which is published by the CMA annually and contains information on the DELs and affected provinces by each TC. Another TC-induced DELs dataset at the county level from 2009 to 2015 for 24 TCs was provided by the National Disaster Reduction Center of China, Ministry of Civil Affairs. Note that TC-induced DELs were recorded by the replacement costs required to repair the damaged properties. Property damage caused by TC-induced severe wind, rainfall, and secondary disasters, such as landslides and flooding, was included in the DELs. Indirect economic losses and long-term impacts were not recorded.

Note that we adjusted the GDP, asset value, and DELs to the price level of 2015 using the GDP deflator, price indices of investments in fixed assets, and consumer price index (CPI) in China (Table 1), respectively, to make the inflation-adjusted data comparable. Finally, we translated these adjusted values in CNY to USD using the exchange rate in 2015 ( 1 USD $=6.2284 \mathrm{CNY}$; Wu et al. 2018a). The study area does not include Hong Kong, Macao, or Taiwan due to data limitations.

\section{b. Methods}

Determining the spatial landscape of a TC is an essential step for economic exposure estimations. A TC may not cause any damage if the daily precipitation is less than $25 \mathrm{~mm}$ and the maximum wind speed is below $17.1 \mathrm{~m} \mathrm{~s}^{-1}$ during its lifetime (Chen et al. 2011). In addition, we referred to the $500-\mathrm{km}$ radius from the TC center used in the latest study (Zhang et al. 2018) as the range of TC-induced extreme precipitation. As such, the TC-affected extent in this study is determined by both the wind field of the TC track and TC-induced precipitation. That is, during a given TC, if an area is hit with daily precipitation surpassing $25 \mathrm{~mm}$ or wind speeds exceeding $17.2 \mathrm{~m} \mathrm{~s}^{-1}$ within a $500-\mathrm{km}$ buffer of the TC path (as shown in Fig. 1 for an example), then this area will be defined as the affected extent of this TC. Economic exposure was further estimated by the accumulated GDP or asset value in the area of the TC-affected extent.

\section{1) WIND FIELD MODEL}

The time interval of a TC track from the CMA described above is $6 \mathrm{~h}$, which is too coarse to model the wind field. That is, the buffers of recorded points established based on the wind field model are not continuous and cannot completely cover the TC-affected extent. Therefore, this study interpolated nine points equidistantly between every two consecutive TC points by linear spline referenced from Li et al. (2014), and the temporal resolution was increased to $0.6 \mathrm{~h}$ (Yin et al. 2014).

Key parameters of a TC, such as central pressure and the radius of maximum wind (RMW), are used to simulate the pressure profile model. The extended 

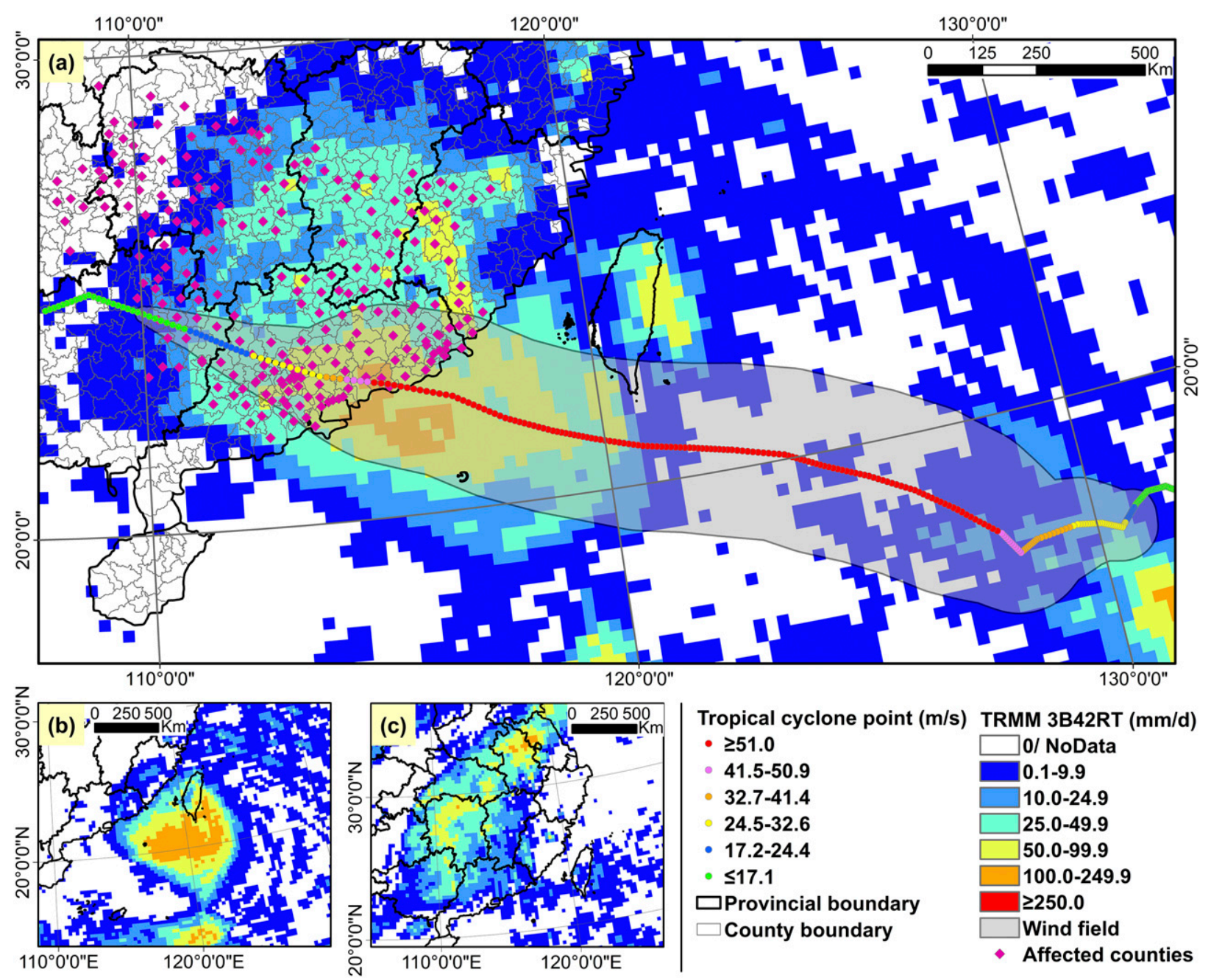

FIG. 1. Affected extent of Typhoon Usagi (1319), which made landfall in Guangdong Province, China, on 22 Sep 2013. Precipitation distribution (a) on 22 Sep and (b) before and (c) after landfall is shown. The pink diamonds represent the simulated affected counties determined by both the wind field and precipitation via the methods described in the text.

pressure field, as shown by Holland (1980, 2008), is as follows:

$$
p_{r}=p_{c}+\left(p_{\infty}-p_{c}\right) \exp \left[-\left(R_{w} / r\right)^{B}\right],
$$

where $p_{r}$ is the pressure $(\mathrm{hPa})$ at radial distance $r ; p_{c}$ is the minimum pressure (hPa) near the TC center; $p_{\infty}$ is the ambient pressure $(\mathrm{hPa}) ; B$ is the Holland $B$ parameter defining the shape of the wind profile for describing the radial distribution of pressure and is set to 1 without considering its sensitivity to latitude and translational speed (Holland 2008; Lin and Fang 2013); and $R_{w}$ is the radius of maximum wind $(\mathrm{km})$, which refers to the distance from the maximum wind speed of the wind profile to the center of a TC. The value of $R_{w}$ reflects the possible affected extent of the TC with high velocity and has an important influence on the simulation of the wind speed and pressure of the TC. The model for $R_{w}$ was empirically presented by Lin and Fang (2013) as follows:

$$
R_{w}=-18.04 \ln \left(p_{\infty}-p_{c}\right)+110.22 .
$$

The value of $p_{r}$ in pressure profile model (1) corresponding to a wind speed of $17.2 \mathrm{~m} \mathrm{~s}^{-1}$ is $998 \mathrm{hPa}$, which was calculated according to the Dvorak Current Intensity Chart measured by the Joint Typhoon Warning Center (JTWC). Hence, the wind speed radii $r$ for the wind speed threshold $17.2 \mathrm{~m} \mathrm{~s}^{-1}$ are as follows:

$$
r=-\frac{R_{w}}{\ln \left(p_{r}-p_{c}\right)-\ln \left(p_{\infty}-p_{c}\right)} .
$$

Finally, for each TC point, the wind field can be modeled as described above, and the TC-affected 
extent due to wind can be determined by the union areas with wind speeds greater than $17.2 \mathrm{~m} \mathrm{~s}^{-1}$ during a TC event (an example is shown in Fig. 1).

\section{2) TROPICAL CYCLONE-INDUCED PRECIPITATION EXTENT EXTRACTION}

For certain TCs, strong winds and TC-induced rainfall are important consequences; thus, the TC-induced intense precipitation is a trending topic in the TC research community (Chen et al. 2010; Wang et al. 2009). We used the daily precipitation synthesized by the abovementioned 3-h precipitation data as a determinant to delineate the affected areas due to TC-induced precipitation. Thus, the areas with daily precipitation surpassing $25 \mathrm{~mm}$ within $500 \mathrm{~km}$ of a TC path are extracted as the affected extent of the TC-induced extreme precipitation (an example is shown in Fig. 1).

\section{3) ECONOMIC EXPOSURE ANALYSIS METHOD}

Based on the wind-rainfall method described above, we first reconstructed the TC-affected extent for each TC during the period of 2000-15 based on the analysis of an extensive database of TC tracks coupled with the TRMM dataset. Then, counties affected by TCs at least once during the 16 years could be extracted, and they are subsequently referred to as TC-prone areas. The GDP and asset value within the TC-prone areas were then extracted and aggregated to analyze the historical and future spatiotemporal changes associated with economic exposure based on different frequency levels and in different provinces and different latitude zones.

For future projections of the GDP of China, three SSPs were used in the TC-related economic exposure projections: SSP1 characterizes a world pursuing sustainable development, SSP2 assumes that historical trends will continue under medium challenges, and SSP3 is characterized by the widening gap between rich and poor (Leimbach et al. 2017). The gridded GDPs downloaded from CGER were aggregated to different scales (i.e., different affected frequency areas, provinces, and latitude zones) to obtain the GDP growth rate in the future under different GDP growth trajectories, and these rates were used to estimate the GDP exposure to TCs in the twenty-first century. Turning to asset value, we assumed that asset value exposure will have the same growth trajectories as GDP under SSPs due to the lack of relevant research results.

\section{Results}

\section{a. Difference in exposure estimation of using wind-only and wind-rainfall methods}

To determine whether using the wind field only or the wind and rainfall fields simultaneously produces different impacts when assessing economic exposure, we assessed three TCs (i.e., Typhoon Rammasun, Typhoon Kalmaegi, and severe Tropical Storm Fung-wong) that achieved landfall on the mainland of China in 2014 with different landfall intensities (Fig. 2) and compared the two methods of determining TC-affected extent based on the number of affected counties, asset value exposure, and TCinduced DELs (Table 2). Figure 2 points out the key issue of concern: the three TCs made landfall with maximum central wind speeds of approximately 60 (Fig. 2a), 40 (Fig. 2b), and $28 \mathrm{~m} \mathrm{~s}^{-1}$ (Fig. 2c), respectively, but only reached a narrow area. The extent of TC-induced heavy precipitation covered a large landscape, which could be potentially catastrophic to the exposed population and economies.

The results presented in Fig. 2 and Table 2 show that using the wind field only (wind-only method) substantially underestimated the TC-affected extent for the three TCs, while using both the wind and rainfall fields (wind-rainfall method) largely improved the accuracy. For Typhoon Rammasun, Typhoon Kalmaegi, and severe Tropical Storm Fung-wong, only 56.6\%, 28.7\%, and $38.2 \%$ of the historical recorded counties were captured by the wind-only method, whereas $80.8 \%$, $71.3 \%$ and $47.1 \%$ of the recorded counties were captured when both the wind and rainfall fields were considered as used in this study, respectively. The average percentage of the number of affected counties for seven so-called TC-provinces (per TC event for the respective provinces; Table 2) improved from $41.5 \%$ (wind-only method) to $71.8 \%$ (wind-rainfall method).

Under Typhoon Rammasun, Typhoon Kalmaegi, and severe Tropical Storm Fung-wong, 76.8\%, 88.4\%, and $58.9 \%$ of the total DELs in the simulated affected counties were obtained using the wind-rainfall method, whereas only $58.5 \%, 67.0 \%$, and $53.7 \%$ of the total DELs were obtained by the wind-only method, respectively. The average percentage of accumulative DELs for seven TC-provinces improved from $60.9 \%$ (windonly method) to $79.9 \%$ (wind-rainfall method).

A more complicated situation is observed when assessing the asset value exposure. In certain TCprovinces, such as TC-province Guangxi impacted by Typhoon Rammasun, the asset value exposure was overestimated by both the wind-only and windrainfall methods. However, both methods may underestimate the exposed asset value in other TCprovinces, such as TC-province Guangdong impacted by Typhoon Kalmaegi; yet, the wind-rainfall method still improved the result by $54.6 \%$. TC-province Hainan impacted by Typhoon Kalmaegi, for instance, represents another situation in which the wind-only method underestimated the asset value exposure, while the wind-rainfall method overestimated this value. It is 


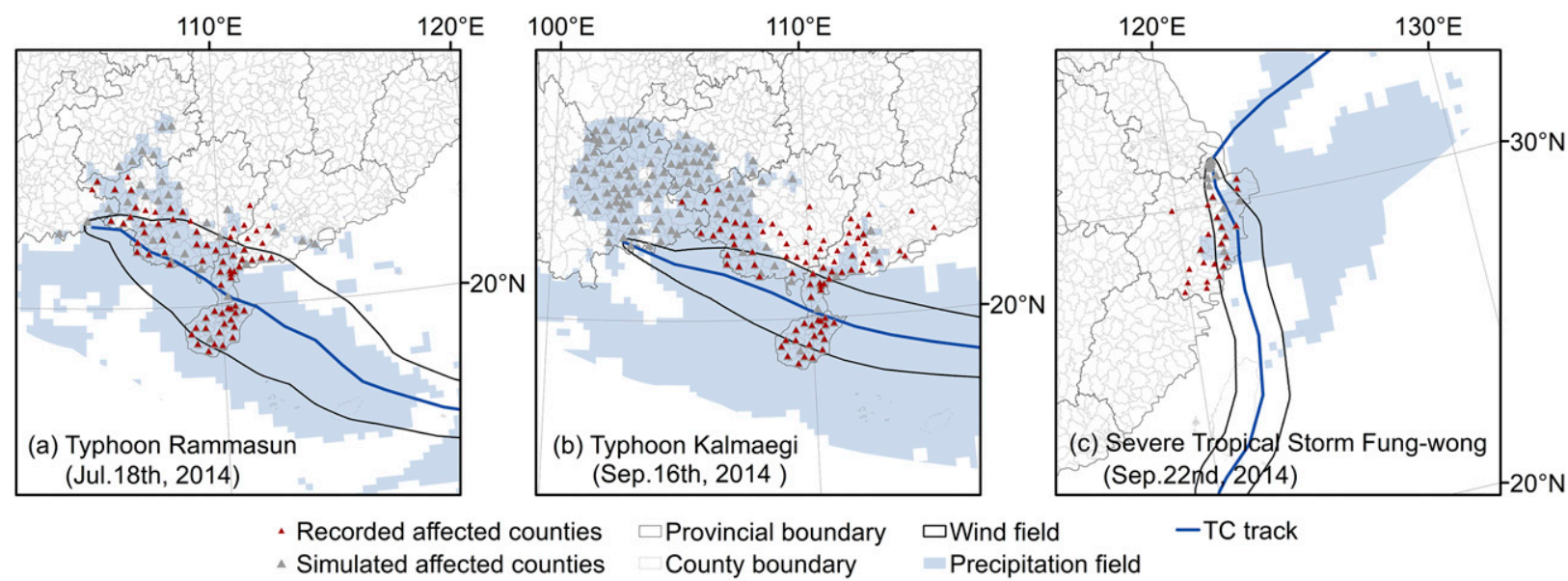

FIG. 2. Comparison of TC-affected counties for (a) Typhoon Rammasun, (b) Typhoon Kalmaegi, and (c) severe Tropical Storm Fungwong among the TC-affected counties (gray triangles) simulated using the wind-rainfall method as described in the text and the actual affected counties (dark red triangles) that suffered DELs.

worth noting that the simulated extent of TCs included some unaffected counties, especially for Typhoon Kalmaegi, while several actual affected counties were not contained (Fig. 2). We will discuss the uncertainties in the data and method in the following section.

The relationship between TC-induced DELs and simulated asset value exposure per TC-province during the period from 2000 to 2015 also demonstrates the important role of rainfall in effective economic exposure estimations (Fig. 3). The wind-rainfall method identified 317 TC-provinces, whereas the wind-only method identified 210 TC-provinces. The coefficient of determination of the wind-rainfall method $(R=$ 0.428 ; Fig. 3a) is much higher than that of the windonly method ( $R=0.232$; Fig. $3 \mathrm{~b})$, which highlights the importance of including the rainfall field.

Thus, in addition to considering the wind field, the extreme rainfall induced by TCs should also be considered to improve the accuracy of economic exposure estimations as described above.

\section{b. Historical economic exposure change by affected frequency and latitude zones}

Based on the wind-rainfall method, TC-prone counties with different affected frequencies during the period from 2000 to 2015 were extracted (as shown in Fig. 4). Figure 4 shows that TC-prone areas covered 1362 counties. Of these, 871 counties were distributed in low-frequency (LF) areas, which were affected by TCs fewer than 8 times during the 16 years; 242 counties were distributed in middle-frequency (MF) areas (9-16 times); and the remaining 249 counties were concentrated in highfrequency (HF) areas (more than 16 times).

As shown in Fig. 4, China lies to the west of the North Pacific Ocean and is frequently affected by TCs. Overall, in $2015,66.7 \%$ of the GDP [approximately CNY 48.6 trillion (7.8 trillion USD)] and $63.9 \%$ of the asset value

TABLE 2. Evaluation of the number of affected counties, asset value exposure, and DELs among the historical records and simulation results using the wind-only and wind-rainfall methods.

\begin{tabular}{|c|c|c|c|c|c|c|c|c|c|c|}
\hline \multirow[b]{2}{*}{$\mathrm{TC}$} & \multirow[b]{2}{*}{$\begin{array}{c}\mathrm{TC}- \\
\text { province }\end{array}$} & \multicolumn{3}{|c|}{ Number of affected counties } & \multicolumn{3}{|c|}{$\begin{array}{l}\text { Asset value exposure } \\
\text { (billion CNY) }\end{array}$} & \multicolumn{3}{|c|}{ DELS (billion CNY) } \\
\hline & & Records & $\begin{array}{l}\text { Wind } \\
\text { only }\end{array}$ & $\begin{array}{l}\text { Wind- } \\
\text { rainfall }\end{array}$ & Records & $\begin{array}{l}\text { Wind } \\
\text { only }\end{array}$ & $\begin{array}{l}\text { Wind- } \\
\text { rainfall }\end{array}$ & Records & $\begin{array}{l}\text { Wind } \\
\text { only }\end{array}$ & $\begin{array}{l}\text { Wind- } \\
\text { rainfall }\end{array}$ \\
\hline \multirow[t]{3}{*}{ Rammasun (1409) } & Guangdong & 21 & 15 & 19 & 1187.00 & 1204.77 & 1653.53 & 15.86 & 8.34 & 15.83 \\
\hline & Guangxi & 57 & 24 & 40 & 1692.97 & 3239.98 & 4119.15 & 13.90 & 4.18 & 4.25 \\
\hline & Hainan & 21 & 17 & 21 & 1313.61 & 1145.71 & 1510.94 & 11.91 & 11.86 & 11.91 \\
\hline \multirow[t]{3}{*}{ Kalmaegi (1415) } & Guangdong & 36 & 7 & 20 & 2392.85 & 541.93 & 1847.78 & 8.75 & 5.04 & 8.32 \\
\hline & Guangxi & 51 & 10 & 36 & 1652.41 & 1201.71 & 3350.20 & 3.11 & 1.15 & 1.50 \\
\hline & Hainan & 21 & 14 & 21 & 1313.61 & 1014.07 & 1510.94 & 5.78 & 5.63 & 5.78 \\
\hline Fung-wong (1416) & Zhejiang & 34 & 13 & 16 & 2170.93 & 3694.96 & 3898.50 & 0.95 & 0.51 & 0.56 \\
\hline
\end{tabular}




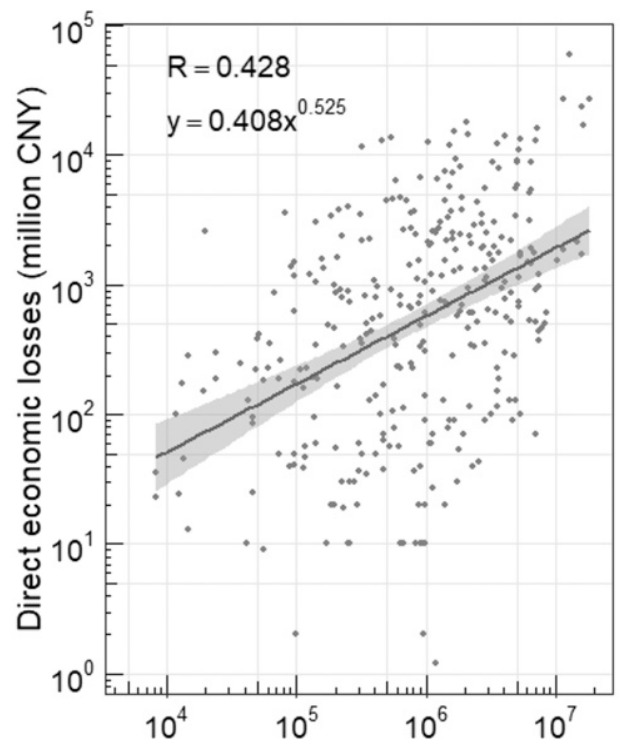

(a) Simulated asset value exposure (million CNY)

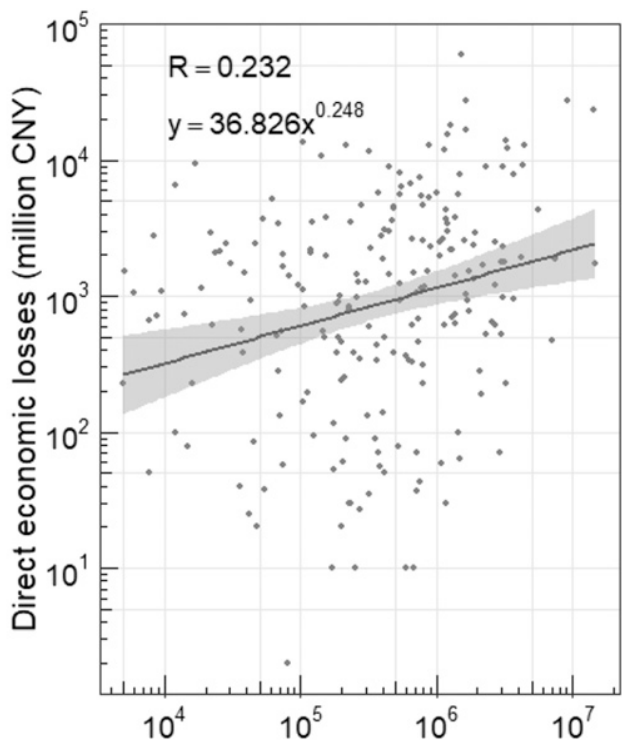

(b) Simulated asset value exposure (million CNY)

FIG. 3. Relationship between TC-induced DELs and simulated asset value exposure at the TC-province level during the period from 2000 to 2015. A province affected by a TC is defined as an event (referred to as a TCprovince) indicated with a point. The DELs and asset value represent a TC-province's actual recorded DELs and simulated asset value exposed to that TC using (a) the wind-rainfall method and (b) the wind-only method. The $x$ and $y$ axes are on a denary logarithmic scale. The gray areas are the $95 \%$ confidence intervals.

[approximately CNY 139.5 trillion (22.4 trillion USD)] of China were exposed to TC-prone areas (as shown in Table 3). From the aspect of TC-affected frequency, $58.1 \%$ of the total GDP (CNY 28.2 trillion) and $62.3 \%$ of the total asset value in TC-prone areas (CNY 86.8 trillion) were distributed in LF counties. For HF counties, the proportions of the GDP (CNY 11.2 trillion) and asset value (CNY 28.3 trillion) were $22.9 \%$ and $20.3 \%$, respectively, while MF counties accounted for the smallest proportion. In addition, $91.8 \%$ of the GDP (CNY 10.2 trillion) and $87.8 \%$ of the asset value (CNY 24.9 trillion) in HF counties were concentrated in the east economic zone (Table 3 ), while only $8.2 \%$ of the GDP and $12.2 \%$ of the asset value in HF counties were concentrated in the central and west China zones, respectively.

From a historical perspective, the total GDP in TC-prone areas increased by more than 11-fold from CNY 3.9 trillion in 1990 to CNY 48.6 trillion in 2015, with a net growth of CNY 44.7 trillion (Table 4). The GDP in TC-prone areas grew at an average annual rate of $10.6 \% \mathrm{yr}^{-1}$ over the 25 years. The total asset value in TC-prone areas increased by 25 -fold from CNY 5.4 trillion in 1990 to CNY 139.5 trillion in 2015, an increase of CNY 134.1 trillion at an average annual rate of $13.9 \%$, which was slightly faster than the rate in the mainland of China. The percentage of GDP in TC-prone areas of
China increased from $65.8 \%$ in 1990 to $67.1 \%$ in 2015 , while the percentage of the asset value in TC-prone areas of China increased from $63.6 \%$ in 1990 to $63.9 \%$ in 2015.

To dissect the economic exposure to TCs in the years 2010 and 2050, we parsed out the east economic zone to the provincial level (Fig. 5). Figure 5 shows that for the total GDP exposure, Jiangsu, Guangdong, and Zhejiang Provinces were ranked the top three and accounted for CNY 4.6, 4.1, and 3.1 trillion GDP exposure in 2010, respectively. For the GDP exposure in HF areas, Guangdong, Zhejiang, and Fujian Provinces were ranked the top three and accounted for CNY 4.0, 1.6, and 1.5 trillion GDP exposure, respectively.

In the latitude zones in $2^{\circ}$ increments starting at $18^{\circ} \mathrm{N}$ and extending to $50^{\circ} \mathrm{N}$ iteratively thereafter, Fig. 5 shows that the economic exposure to TCs presented large spatial heterogeneity from northern to southern China. The $2^{\circ}$ belt from $30^{\circ}$ to $32^{\circ} \mathrm{N}$, which includes northern Zhejiang, Shanghai, and southern Jiangsu, covered the densest GDP exposure of CNY 7.5 trillion in 2010, which increased almost eightfold, compared to that in 1990 . Trailing behind was the $22^{\circ}-$ $24^{\circ} \mathrm{N}$ belt, which reached CNY 4.3 trillion of GDP exposure. The $8^{\circ}$ belt from $26^{\circ}$ to $34^{\circ} \mathrm{N}$ reached $\mathrm{CNY}$ 15.6 trillion of GDP exposure in 2010. Overall, the GDP exposed to TCs did not show a logical distribution of 


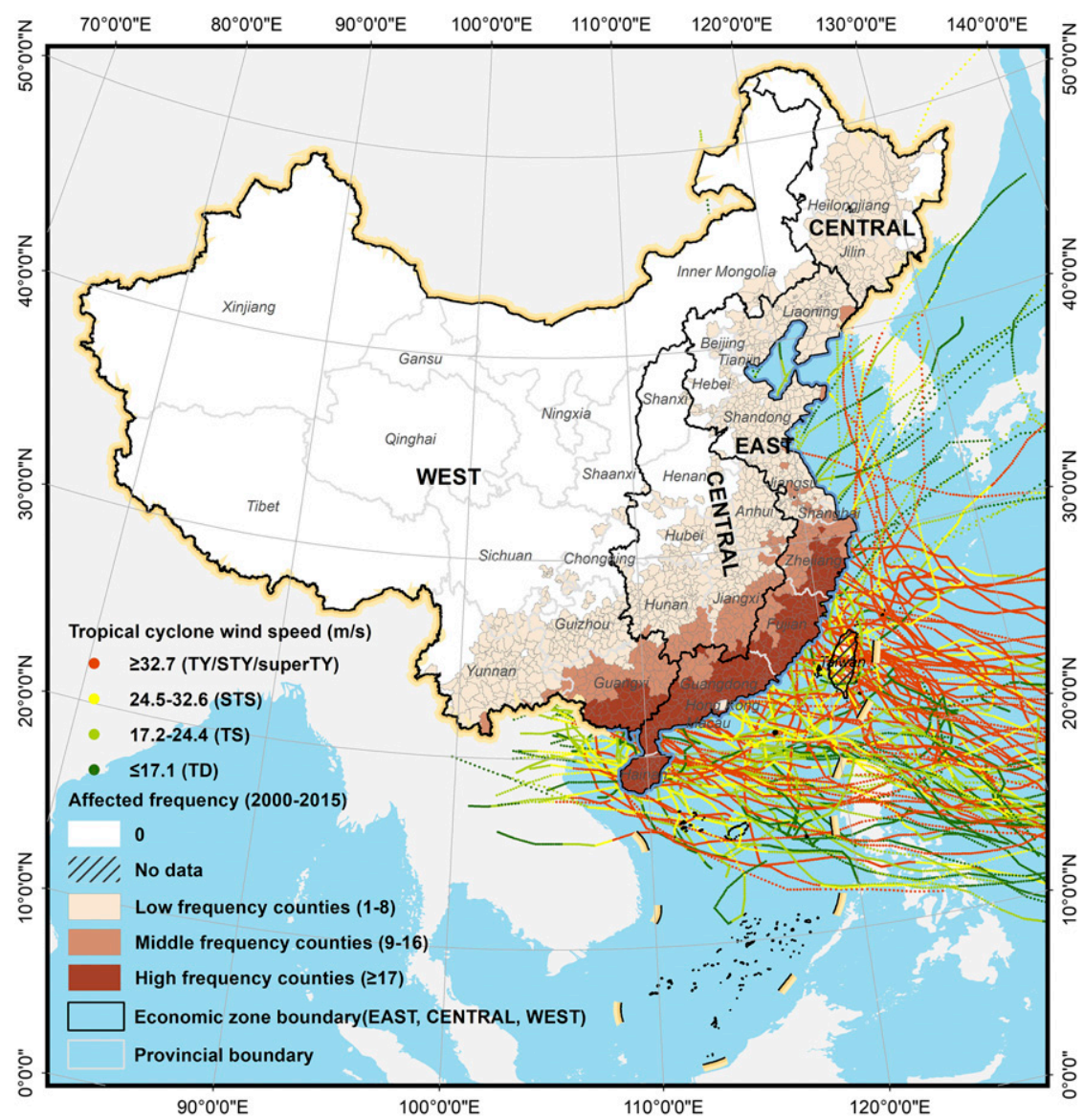

FIG. 4. TC tracks labeled with wind speed (via linear interpolation) for the period of 2000-15 in China. The economic zone (east, west, and central) boundaries are based on the definition of the Ministry of Housing and Urban-Rural Development of China (http://www.mohurd.gov.cn/).

higher values in the south to lower values in the north of China.

\section{c. Future changes in economic exposure to TCs in the twenty-first century}

For the TC-affected frequency level, we estimated the GDP and asset value exposure in TC-prone areas of China from 2020 to 2100 under SSP1, SSP2, and SSP3. Figure 6 illustrates that TC-prone areas had experienced an economic surge from 1990 to 2015 and were expected to swell in the rest of the twenty-first century. Under SSP3 and SSP1, however, a downturn in absolute economic exposure level occurred in the 2050s and 2060s after sharp growth. The ranking of the long-term GDP and asset value exposure located in TC-prone areas were quite distinct with respect to GDP growth trajectories under the SSPs. SSP2 exhibited the highest GDP exposure (approximately CNY 242.0 trillion) and asset value

TABLE 3. GDP and asset value exposed to TCs in TC-prone areas with different affected frequencies in three economic zones of China in 2015 (2015 values; trillion CNY). Total in TC-prone areas indicates the sum of the GDP or asset value in each economic zone with different frequency levels.

\begin{tabular}{|c|c|c|c|c|c|c|c|c|}
\hline & \multicolumn{4}{|c|}{ GDP (trillion CNY) } & \multicolumn{4}{|c|}{ Asset value (trillion $\mathrm{CNY}$ ) } \\
\hline & East & Central & West & Total & East & Central & West & Total \\
\hline High frequency & 10.24 & 0.03 & 0.88 & 11.15 & 24.87 & 0.07 & 3.38 & 28.32 \\
\hline Middle frequency & 7.42 & 1.04 & 0.76 & 9.22 & 18.57 & 2.65 & 3.10 & 24.32 \\
\hline Low frequency & 14.81 & 10.74 & 2.68 & 28.23 & 44.66 & 32.93 & 9.25 & 86.84 \\
\hline Total in TC-prone areas & 32.47 & 11.82 & 4.32 & 48.61 & 88.10 & 35.65 & 15.73 & 139.48 \\
\hline Total in China's mainland & 40.09 & 17.89 & 14.92 & 72.90 & 108.08 & 57.47 & 52.82 & 218.37 \\
\hline
\end{tabular}


TABLE 4. Changes in GDP and asset value in the TC-prone areas from 1990 to 2015 (2015 values; trillion CNY). Here, we use (GDP2015/GDP1990) to calculate the GDP change rate, where GDP2015 and GDP1990 are the exposed GDP in 2015 and 1990, respectively. The GDP growth rate is calculated by [(GDP2015/GDP1990) $\left.)^{1 / 25}-1\right] \times 100 \%$, which indicates the average annual growth rate of GDP exposure over the last 25 years. The methods used to calculate the change rate and growth rate of the asset value exposure are the same as that for GDP.

\begin{tabular}{|c|c|c|c|c|c|c|c|c|c|c|c|c|}
\hline \multirow[b]{2}{*}{ Area } & \multicolumn{4}{|c|}{ GDP (trillion CNY) } & \multicolumn{4}{|c|}{ Asset value (trillion $\mathrm{CNY}$ ) } & \multirow{2}{*}{$\begin{array}{c}\text { GDP } \\
\text { change } \\
\text { rate }(\%)\end{array}$} & \multirow{2}{*}{$\begin{array}{c}\text { Asset } \\
\text { change } \\
\text { rate }(\%)\end{array}$} & \multirow{2}{*}{$\begin{array}{c}\text { GDP } \\
\text { growth } \\
\text { rate (\%) }\end{array}$} & \multirow{2}{*}{$\begin{array}{c}\text { Asset } \\
\text { growth } \\
\text { rate }(\%)\end{array}$} \\
\hline & 1990 & 2000 & 2010 & 2015 & 1990 & 2000 & 2010 & 2015 & & & & \\
\hline High frequency & 0.83 & 2.88 & 7.75 & 11.16 & 0.81 & 3.41 & 14.59 & 28.32 & 13 & 34.80 & 10.93 & 15.26 \\
\hline Middle frequenc & 0.76 & 2.20 & 6.43 & 9.22 & 0.95 & 3.69 & 14.55 & 24.32 & 12.08 & 25 . & & 13.86 \\
\hline Low frequency & 2.33 & 6.25 & 19.47 & 28.23 & 3.65 & 10.15 & 44.81 & 86.84 & 12.11 & 23.81 & 10 & 13.52 \\
\hline Total of TC-prone & 3.93 & 11.33 & 33.65 & 48.61 & 5.41 & 17.25 & 73.96 & 139.48 & 12.37 & 25.78 & 10.58 & 13.88 \\
\hline Total of China's mainland & 5.97 & 16.60 & 50.17 & 72.90 & 8.50 & 26.14 & 112.45 & 218.37 & 12.21 & 25.69 & 10.53 & 13.87 \\
\hline
\end{tabular}

exposure (approximately CNY 702.6 trillion) in 2100 , followed by SSP1 (with approximately CNY 172.9 trillion for GDP and CNY 487.1 trillion for asset value) and SSP3 (approximately CNY 141.3 trillion for GDP and CNY 409.5 trillion for asset value).

Further, we chose SSP2, which is a "middle of the road" scenario, to project the GDP growth pattern at different scales. At the provincial level (Fig. 5), the top three provinces for total GDP exposure under SSP2 in 2050 are Jiangsu (CNY 26.8 trillion), Guangdong (CNY 24.2 trillion), and Zhejiang (CNY 18.6 trillion), which is the same order as in 2010. For the HF areas, Guangdong Province is first at CNY 23.3 trillion, followed by Fujian
(CNY 10.0 trillion) and Zhejiang (CNY 9.9 trillion). For latitude zones (Fig. 5), the highest density of GDP exposure was located in the latitude belt from $26^{\circ}$ to $34^{\circ} \mathrm{N}$ at CNY 80.1 trillion of GDP exposure in 2050, and this value increases to CNY 89.0 trillion in 2100 .

\section{Discussion}

\section{a. Importance of rainfall in TC-related economic exposure estimation}

For a physical event to be hazardous and damaging, a population and/or assets must be exposed to the threat (Pelling et al. 2004). Previous studies have investigated

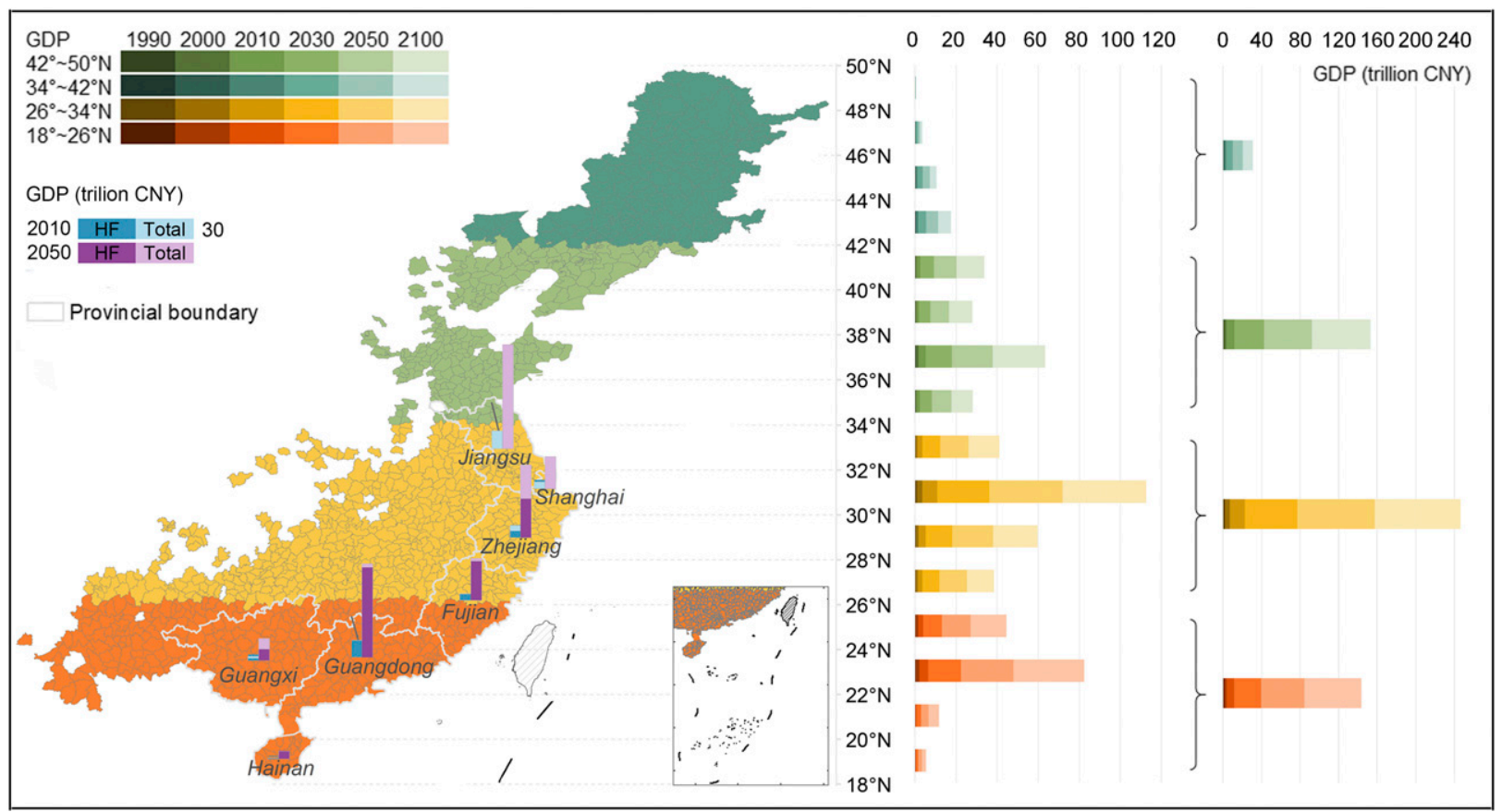

FIG. 5. GDP exposed to TC-prone areas at different latitude zones of China (2015 values; trillion CNY). GDP exposure in the latitude zone divided into $8^{\circ}$ increments is also shown. Estimated GDP exposures for 2030, 2050, and 2100 were based on the growth rate of GDP under SSP2 from CGER (http://www.cger.nies.go.jp/en/). 


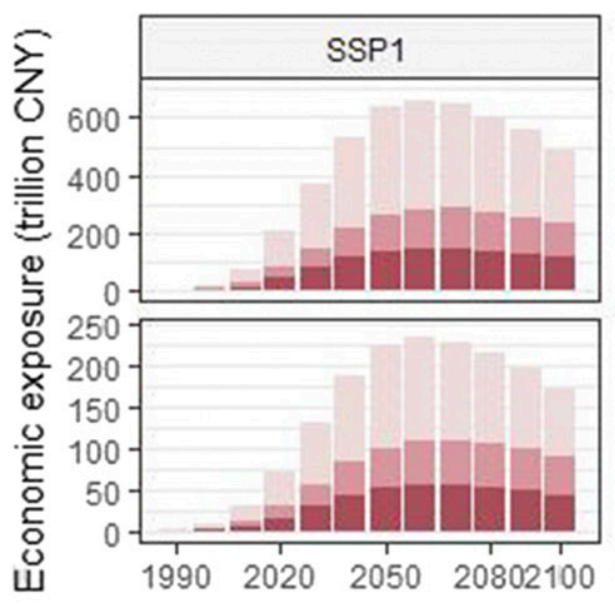

Low frequency
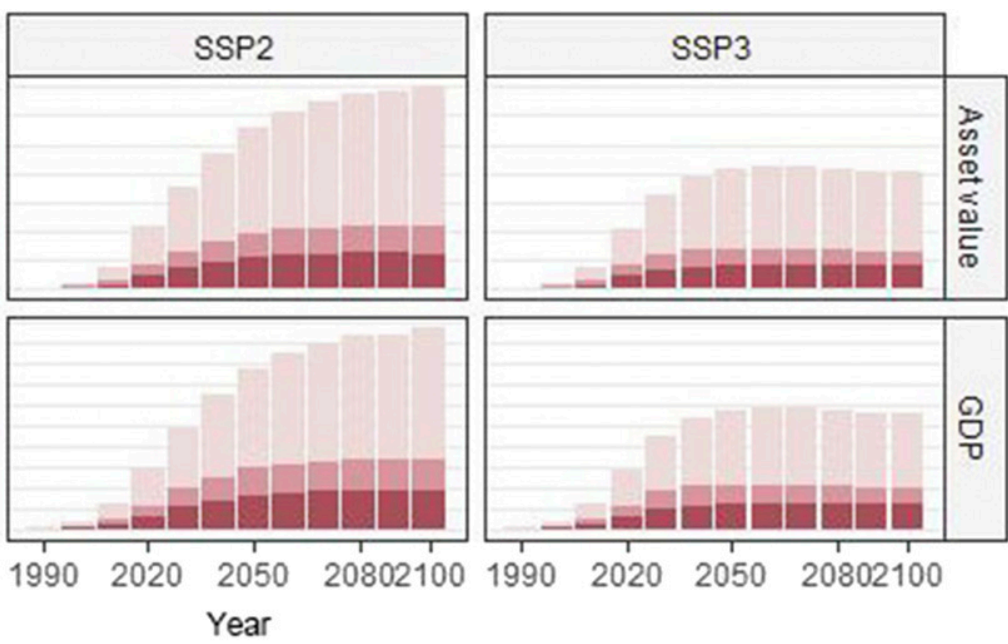

$199020202050 \quad 20802100$

Middle frequency

High frequency

FIG. 6. GDP and asset value in TC-prone areas in China with different affected frequencies (2015 values; trillion CNY) under (left) SSP1, (center) SSP2, and (right) SSP3. Growth rate of GDP is calculated based on the global dataset of GDP scenarios downloaded from CGER. Asset value is measured as (Asset2015/GDP2015) $\times($ GDP of that year) and assuming a consistent growth ratio between the asset value and GDP.

populations and/or assets exposed to natural hazards as key drivers underlying the increasing impacts of natural hazard-induced disasters (Ashley et al. 2014; Ashley and Strader 2016; Cardona et al. 2012; Rosencrants and Ashley 2015; Noy 2016). To better understand the relationship between TC-induced DELs and economic exposure, we first reconstructed the historical asset value exposure of 114 TCs from 2000 to 2015 based on an overlay analysis of a county-level asset value dataset and the TCaffected counties as described above, with each TC causing damage to at least one province. As Fig. 3a shows, the TC-induced DELs followed a straight line on a loglinear scale and were positively correlated with the related asset value exposure. Note that only economic exposure impacted by TCs was examined in this study, and the model will be greatly improved after vulnerability factors are added.

Furthermore, disaster risk reflected in various interactions among aspects is synthetically assessed by a conceptual framework of hazard, exposure, and vulnerability, and certain assessments also consider the adaptive capacity (Brooks 2003; Marin-Ferrer et al. 2017; Pelling et al. 2004; Vatsa 2004). Thus, systematically assessing TC risks requires determining how TCs will change in intensity and frequency under climate change scenarios in the future and identifying the interactions between TC hazards and the changing economic exposure associated with social development (Noy 2016).

For TC risks in China, coastal areas may be better adapted to TCs and less vulnerable because of their active adaptation policies and high precautionary measures; conversely, these areas may be more vulnerable to TCs because of misleading economic development patterns (Mendelsohn et al. 2012). Developing methods of systematically analyzing TC risks via a conceptual model that considers the hazards, exposure, and vulnerability is a trending topic for future research (e.g., Ciurean et al. 2013; Marin-Ferrer et al. 2017; Jongman et al. 2015).

\section{b. Limitations}

Some limitations exist in our study. First, inherent defects are involved in using the method applied here for determining TC-affected extent:

1) For the wind field model, we constructed a smooth wind field for a given TC from genesis to dissipation, and the potential effects of latitude and topography on reducing TC strength were neglected (Holland 2008; Lin and Fang 2013).

2) For the precipitation-affected extent, whether a fixed radius of $500 \mathrm{~km}$ from the TC center can be used to detect the TC-induced precipitation was uncertain because a TC can involve predecessor rain events resulting from synoptic climatology beyond $1000 \mathrm{~km}$ from the TC center (Galarneau et al. 2010; Zhang et al. 2018). However, enlarging the radius may cover precipitation associated with other weather systems (Hasegawa and Emori 2005).

3) The wind field and precipitation data for the duration of TCs are used to determine the TC-affected extent, and the consequential storm surges and the rogue waves caused by TCs have been left aside. 
4) For the precipitation data, limited data were available, and the precipitation data "TRMM 3B42RT" were accessible only from 2000; therefore, we used 114 TCs with DEL records from 2000 to 2015 to reconstruct the history of TC-affected counties. However, these records may not represent the full potential of TCs. Nevertheless, the existing DEL data of TC events on a provincial scale are inadequate to verify the accuracy of the method in this study, and we only used three TCs (Fig. 2) that have county-level DELs records for confirmation. Further, such county-level disaster records collections would be useful for verifying the TCaffected extent identification method.

Second, since accurately projecting the activities of TCs in the future represents an intractable issue because of the large uncertainties, changes in both the frequency and path of TCs in the future were not considered in the TC-related economic exposure projection. Moreover, detecting trends in historical TC activities is complex and subject to considerable uncertainties, and datum divergence corroborates these controversies (Sobel et al. 2016). Emanuel (2005) showed that the total energy dissipation of hurricanes has increased dramatically since the mid-1970s because durations are longer and intensities are greater than ever. Webster et al. (2005) concluded that the number and proportion of category 4 and 5 hurricanes in 2005 were almost double those of 1970 globally. Taking advantage of highresolution climate models, recent studies have debated future changes in TC tracks and frequency of occurrence over the WNP. Kossin et al. (2016) indicated that more TCs will recurve northward in the future. Murakami et al. (2012) projected a northeastward migration of TC track resulting from the combination of poleward and eastward shifts. Stowasser et al. (2007) applied a regional model and indicated that global warming will result in a dramatic increase in TCs in the South China Sea. Emanuel (2013) downscaled the climate models of phase 5 of the Coupled Model Intercomparison Project (CMIP5) and concluded that the TC frequency will increase over the twenty-first century. Considering the fact that projections of track migration and frequency of TCs in a given region remain equivocal, the combination of both aspects has a compounding effect (frequency decreases in concert with track migrating away from the region) or an offsetting effect (the change of frequency and track migration is the opposite) may lead to considerable variations in TC exposure (Kossin et al. 2016). Further studies using high-resolution TC projection results to estimate changes in TC-related spatiotemporal economic exposure would be beneficial for understanding the change of TC risk.

Finally, large uncertainties are involved in projecting GDP scenarios throughout the twenty-first century
(Leimbach et al. 2017; Dellink et al. 2017). The projecting approach itself has considerable uncertainty, and severe external shocks, such as natural hazards and wars, can break out and to some extent abruptly change projections chronically and may even alter economic development trajectories permanently in particularly severe cases (Dellink et al. 2017). Moreover, it remains to be further studied how to project asset value growth trajectories more accurately instead of replacing them with GDP scenarios. Therefore, the projections should be interpreted with adequate caution.

\section{Conclusions}

Based on analyses of an extensive database of TC tracks coupled with a TRMM dataset and wind field model, we first reconstructed the wind field and the extent of TC-induced rainfall for each TC for the period of 2000-15 to determine the TC-affected extent. We further verified that considering the wind field exclusively led to underestimations in terms of the number of affected counties, asset value exposure, and TC-induced DELs. However, adding rainfall as another factor could improve the economic exposure estimations as well as the relationship between asset value exposure and DELs. Overall, TC-induced precipitation is an important dimension for determining TC-affected extent.

Furthermore, this study provides a long-term estimation of historical and future economic exposure to TCs from 1990 to 2100 using GDP and asset value as indicators at different scales. The development of the Chinese economy and society triggered a substantial increase in both GDP and asset value in areas exposed to TCs in China between 1990 and 2015. We found that $66.7 \%$ of the GDP [CNY 48.6 trillion (7.8 trillion USD)] and $63.9 \%$ of the asset value [CNY 139.5 trillion (22.4 trillion USD)] of China were concentrated in TC-prone areas in 2015. The total GDP in TC-prone areas increased by 11-fold from 1990 [CNY 3.9 trillion (0.6 trillion USD)] to 2015 [CNY 48.6 trillion (7.8 trillion USD)], thus representing an average annual rate of $10.6 \%$ over the past 25 years. The total asset value presented a 24 -fold rise and reached CNY 139.5 trillion (22.4 trillion USD) in 2015 with a growth rate of $13.9 \%$. We also evaluated the distribution of GDP in different latitude zones and found a large spatial divergence of GDP in the TC-prone areas.

This paper also presents a series of GDP projections under different SSPs. Economic exposure will continue to expand in the early stage of the twenty-first century. However, the range of GDP and asset value levels in TC-prone areas by 2100 will vary markedly under different social and economic development policies. In light of existing research results showing a northward migration of 
TCs, eastern China has been projected to endure increases in economic exposure. Hence, the Chinese government should focus on the changes in exposure in TC-prone areas, especially in eastern China.

Moreover, because TC hazards increasingly interact with ongoing economic growth, determining a method of assessing DELs more systematically through a damage function that considers hazard, exposure, and vulnerability is imperative. The impact of climate change in terms of social and economic aspects is an important topic in current research; however, most climate change impact assessment models are characterized by a lack of compelling empirically derived damage functions. Therefore, further studies must be performed to quantify the relationship between TC-induced DELs and other drivers within a risk framework, and they should focus not only on the hazard and exposure effects, but also on vulnerability effects determined by socioeconomic and physical environment factors. These efforts will provide a sound basis for risk assessment and risk-based adaptive measures.

Acknowledgments. This work was supported by the National Key Research and Development Program (2016YFA0602403) and the National Natural Science Foundation of China (41571492). Many thanks go to the editor and four anonymous reviewers, who provided valuable comments for improving this paper's quality.

\section{REFERENCES}

Ashley, W. S., and S. M. Strader, 2016: Recipe for disaster: How the dynamic ingredients of risk and exposure are changing the tornado disaster landscape. Bull. Amer. Meteor. Soc., 97, 767786, https://doi.org/10.1175/BAMS-D-15-00150.1.

,,-- T. Rosencrants, and A. J. Krmenec, 2014: Spatiotemporal changes in tornado hazard exposure: The case of the expanding bull's-eye effect in Chicago, Illinois. Wea. Climate Soc., 6, 175-193, https://doi.org/10.1175/WCAS-D-13-00047.1.

Bakkensen, L. A., D. S. R. Park, and R. S. R. Sarkar, 2018: Climate costs of tropical cyclone losses also depend on rain. Environ. Res. Lett., 13, 074034, https://doi.org/10.1088/1748-9326/aad056.

Breña-Naranjo, J. A., A. Pedrozo-Acuña, O. Pozos-Estrada, S. A. Jiménez-López, and M. R. López-López, 2015: The contribution of tropical cyclones to rainfall in Mexico. Phys. Chem. Earth, 83-84, 111-122, https://doi.org/10.1016/j.pce.2015.05.011.

Brooks, N., 2003: Vulnerability, risk and adaptation: A conceptual framework. Tyndall Centre for Climate Change Research Working Paper, 20 pp.

Camargo, S. J., and A. H. Sobel, 2005: Western North Pacific tropical cyclone intensity and ENSO. J. Climate, 18, 29963006, https://doi.org/10.1175/JCLI3457.1.

Cardona, O. D., M. K. van Aalst, J. Birkmann, M. Fordham, G. McGregor, and R. Mechler, 2012: Determinants of risk: Exposure and vulnerability. Managing the Risks of Extreme Events and Disasters to Advance Climate Change Adaptation, C. B. Field et al., Eds., Cambridge University Press, 65-108.
Chen, H., L. Yan, W. Lou, H. Xu, and S. Yang, 2011: On assessment indexes of the strength of comprehensive impacts of tropical cyclone disaster-causing factors. J. Trop. Meteor., 27, 139-144.

Chen, L., Y. Li, and Z. Cheng, 2010: An overview of research and forecasting on rainfall associated with landfalling tropical cyclones. Adv. Atmos. Sci., 27, 967-976, https://doi.org/10.1007/ s00376-010-8171-y.

Ciurean, R. L., D. Schröter, and T. Glade, 2013: Conceptual frameworks of vulnerability assessments for natural disasters reduction. Approaches to Disaster Management: Examining the Implications of Hazards, Emergencies and Disasters, InTech, 1-30, https://doi.org/10.5772/55538.

CMA, 2014: China Climate Impact Assessment. China Meteorological Press, 33-39.

_ 2015: China Climate Impact Assessment. China Meteorological Press, 29-34.

Dellink, R., J. Chateau, E. Lanzi, and B. Magné, 2017: Long-term economic growth projections in the Shared Socioeconomic Pathways. Global Environ. Change, 42, 200-214, https://doi.org/ 10.1016/j.gloenvcha.2015.06.004.

Elsner, J. B., J. P. Kossin, and T. H. Jagger, 2008: The increasing intensity of the strongest tropical cyclones. Nature, 455, 92-95, https://doi.org/10.1038/nature07234.

Emanuel, K. A., 2005: Increasing destructiveness of tropical cyclones over the past 30 years. Nature, 436, 686-688, https://doi.org/ 10.1038/nature03906.

— 2013: Downscaling CMIP5 climate models shows increased tropical cyclone activity over the 21 st century. Proc. Natl. Acad. Sci. USA, 110, 12 219-12 224, https://doi.org/10.1073/ pnas. 1301293110.

Freeman, A. C., and W. S. Ashley, 2017: Changes in the US hurricane disaster landscape: The relationship between risk and exposure. Nat. Hazards, 88, 659-682, https://doi.org/10.1007/ s11069-017-2885-4.

Galarneau, T. J., Jr., L. F. Bosart, and R. S. Schumacher, 2010: Predecessor rain events ahead of tropical cyclones. Mon. Wea. Rev., 138, 3272-3297, https://doi.org/10.1175/2010MWR3243.1.

Geiger, T., K. Frieler, and A. Levermann, 2016: High-income does not protect against hurricane losses. Environ. Res. Lett., 11, 084012, https://doi.org/10.1088/1748-9326/11/8/084012.

Gunasekera, R., O. Ishizawa, C. Aubrecht, B. Blankespoor, S. Murray, A. Pomonis, and J. Daniell, 2015: Developing an adaptive global exposure model to support the generation of country disaster risk profiles. Earth-Sci. Rev., 150, 594-608, https://doi.org/10.1016/j.earscirev.2015.08.012.

Hasegawa, A., and S. Emori, 2005: Tropical cyclones and associated precipitation over the western North Pacific: T106 atmospheric GCM simulation for present-day and doubled $\mathrm{CO}_{2}$ climates. SOLA, 1, 145-148, https://doi.org/10.2151/ sola.2005-038.

Holland, G. J., 1980: An analytic model of the wind and pressure profiles in hurricanes. Mon. Wea. Rev., 108, 1212-1218, https://doi.org/ 10.1175/1520-0493(1980)108<1212:AAMOTW >2.0.CO;2.

_ 2008: A revised hurricane pressure-wind model. Mon. Wea. Rev., 136, 3432-3445, https://doi.org/10.1175/2008MWR2395.1.

Hsiang, S. M., and A. S. Jina, 2014: The causal effect of environmental catastrophe on long-run economic growth: Evidence from 6,700 cyclones. NBER Working Paper 20352, 69 pp., https://doi.org/10.3386/w20352.

Huffman, G. J., 2016: TRMM (TMPA-RT) Near real-time precipitation L3 3 hour 0.25 degree $\times 0.25$ degree V7. GES DISC, accessed 10 March 2017, https://doi.org/10.5067/TRMM/ TMPA/3H-E/7. 
— , and Coauthors, 2007: The TRMM Multisatellite Precipitation Analysis (TMPA): Quasi-global, multiyear, combined-sensor precipitation estimates at fine scales. J. Hydrometeor., 8, 38-55, https://doi.org/10.1175/JHM560.1.

Jongman, B., H. C. Winsemius, J. C. Aerts, E. C. de Perez, M. K. van Aalst, W. Kron, and P. J. Ward, 2015: Declining vulnerability to river floods and the global benefits of adaptation. Proc. Natl. Acad. Sci. USA, 112, E2271-E2280, https://doi.org/10.1073/pnas.1414439112.

Knutson, T. R., and Coauthors, 2010: Tropical cyclones and climate change. Nat. Geosci., 3, 157-163, https://doi.org/ 10.1038/ngeo779.

Kossin, J. P., K. A. Emanuel, and S. J. Camargo, 2016: Past and projected changes in western North Pacific tropical cyclone exposure. J. Climate, 29, 5725-5739, https://doi.org/10.1175/ JCLI-D-16-0076.1.

Leimbach, M., E. Kriegler, N. Roming, and J. Schwanitz, 2017: Future growth patterns of world regions-A GDP scenario approach. Global Environ. Change, 42, 215-225, https:// doi.org/10.1016/j.gloenvcha.2015.02.005.

Li, X. Y., W. H. Fang, and W. Lin, 2014: Comparison of interpolation methods for tropical cyclone tracks and their intensity over the northwestern Pacific basin. J. Beijing Norm. Univ. Nat. Sci., 50, 111-116.

Lin, W., and W. Fang, 2013: Regional characteristics of Holland B parameter in typhoon wind field model for Northwest Pacific. Trop. Geogr., 33, 124-132.

Luo, S., J. Miao, T. Niu, C. Wei, and X. Wang, 2011: A comparison of TRMM 3B42 products with rain gauge observations in China. Meteor. Mon., 37, 1081-1090.

Marin-Ferrer, M., L. Vernaccini, and K. Poljansek, 2017: INFORM: Index for Risk Management. JRC Science for Policy Rep. EUR 28655 EN, 90 pp., https://doi.org/10.2760/094023.

Mendelsohn, R., K. Emanuel, S. Chonabayashi, and L. Bakkensen, 2012: The impact of climate change on global tropical cyclone damage. Nat. Climate Change, 2, 205-209, https://doi.org/ 10.1038/nclimate1357.

Moazami, S., S. Golian, M. R. Kavianpour, and Y. Hong, 2013: Comparison of PERSIANN and V7 TRMM Multi-satellite Precipitation Analysis (TMPA) products with rain gauge data over Iran. Int. J. Remote Sens., 34, 8156-8171, https://doi.org/ 10.1080/01431161.2013.833360.

Mori, N., and T. Takemi, 2016: Impact assessment of coastal hazards due to future changes of tropical cyclones in the North Pacific Ocean. Wea. Climate Extremes, 11, 53-69, https:// doi.org/10.1016/j.wace.2015.09.002.

Murakami, D., and Y. Yamagata, 2016: Estimation of gridded population and GDP scenarios with spatially explicit statistical downscaling. arXiv, 21 pp., https://arxiv.org/abs/1610.09041.

Murakami, H., and Coauthors, 2012: Future changes in tropical cyclone activity projected by the new high-resolution MRI-AGCM. J. Climate, 25, 3237-3260, https://doi.org/ 10.1175/JCLI-D-11-00415.1.

Noy, I., 2016: The socio-economics of cyclones. Nat. Climate Change, 6, 343-345, https://doi.org/10.1038/nclimate2975.

Peduzzi, P., B. Chatenoux, H. Dao, A. De Bono, C. Herold, J. Kossin, F. Mouton, and O. Nordbeck, 2012: Global trends in tropical cyclone risk. Nat. Climate Change, 2, 289-294, https:// doi.org/10.1038/nclimate1410.

Pelling, M., and Coauthors, 2004: Reducing disaster risk: A challenge for development. UNDP BCPR Rep., $161 \mathrm{pp}$.

Pielke, R. A., Jr., J. Gratz, C. W. Landsea, D. Collins, M. A. Saunders, and R. Musulin, 2008: Normalized hurricane damage in the United States: 1900-2005. Nat. Hazards Rev., 9, 29-42, https://doi.org/10.1061/(ASCE)1527-6988(2008)9:1(29).

Rosencrants, T. D., and W. S. Ashley, 2015: Spatiotemporal analysis of tornado exposure in five US metropolitan areas. Nat. Hazards, 78, 121-140, https://doi.org/10.1007/s11069-015-1704-z.

Sobel, A. H., S. J. Camargo, T. M. Hall, C. Y. Lee, M. K. Tippett, and A. A. Wing, 2016: Human influence on tropical cyclone intensity. Science, 353, 242-246, https://doi.org/10.1126/science.aaf6574.

Stowasser, M., Y. Wang, and K. Hamilton, 2007: Tropical cyclone changes in the western North Pacific in a global warming scenario. J. Climate, 20, 2378-2396, https://doi.org/10.1175/JCLI4126.1.

United Nations, 2015: World urbanization prospects: The 2014 revision (ST/ESA/SER.A/366). United Nations: DESA/ Population Division, accessed 18 April 2018, http://esa.un.org/ unpd/wup/index.htm.

Vatsa, K. S., 2004: Risk, vulnerability, and asset-based approach to disaster risk management. Int. J. Sociol. Soc. Policy, 24, 1-48, https://doi.org/10.1108/01443330410791055.

Vecchi, G. A., and B. J. Soden, 2007: Effect of remote sea surface temperature change on tropical cyclone potential intensity. Nature, 450, 1066-1070, https://doi.org/10.1038/nature06423.

Wang, D., X. Li, W. K. Tao, Y. Liu, and H. Zhou, 2009: Torrential rainfall processes associated with a landfall of severe Tropical Storm Bilis (2006): A two-dimensional cloud-resolving modeling study. Atmos. Res., 91, 94-104, https://doi.org/10.1016/ j.atmosres.2008.07.005.

Webster, P. J., G. J. Holland, J. A. Curry, and H. R. Chang, 2005: Changes in tropical cyclone number, duration, and intensity in a warming environment. Science, 309, 1844-1846, https:// doi.org/10.1126/science.1116448.

Woodruff, J. D., J. L. Irish, and S. J. Camargo, 2013: Coastal flooding by tropical cyclones and sea-level rise. Nature, 504, 44-52, https://doi.org/10.1038/nature12855.

Wu, J., N. Li, and P. Shi, 2014: Benchmark wealth capital stock estimations across China's 344 prefectures: 1978 to 2012. Chin. Econ. Rev., 31, 288-302, https://doi.org/10.1016/j.chieco.2014.10.008.

_ C. Wang, X. He, X. Wang, and N. Li, 2017: Spatiotemporal changes in both asset value and GDP associated with seismic exposure in China in the context of rapid economic growth from 1990 to 2010. Environ. Res. Lett., 12, 034002, https:// doi.org/10.1088/1748-9326/aa5d47.

— G. Han, H. Zhou, and N. Li, 2018a: Economic development and declining vulnerability to climate-related disasters in China. Environ. Res. Lett., 13, 034013, https://doi.org/10.1088/ 1748-9326/aaabd7.

_ , Y. Li, N. Li, and P. Shi, 2018b: Development of an asset value map for disaster risk assessment in China by spatial disaggregation using ancillary remote sensing data. Risk Anal., 38, 17-30, https://doi.org/10.1111/risa.12806.

Yin, Y., Y. Luo, F. Xiao, and X. Zhu, 2014: Basic climate characteristics of tropical cyclones in count-level administrations of China during 1971-2011. J. Trop. Meteor., 30, 1089-1097.

Ying, M., W. Zhang, H. Yu, X. Lu, J. Feng, Y. Fan, Y. Zhu, and D. Chen, 2014: An overview of the China Meteorological Administration tropical cyclone database. J. Atmos. Oceanic Technol., 31, 287-301, https://doi.org/10.1175/JTECH-D-12-00119.1.

Zhang, Q., Q. Liu, and L. Wu, 2009: Tropical cyclone damages in China 1983-2006. Bull. Amer. Meteor. Soc., 90, 489-496, https://doi.org/10.1175/2008BAMS2631.1.

, X. Gu, J. Li, P. Shi, and V. P. Singh, 2018: The impact of tropical cyclones on extreme precipitation over coastal and inland areas of China and its association to ENSO. J. Climate, 31, 1865-1880, https://doi.org/10.1175/JCLI-D-17-0474.1. 